\title{
EMOTIONAL STRESS ESTIMATION IN GENERAL POPULATION
}

\author{
Maria Altaf', Shamoon Noushad ${ }^{2}$, Sadaf Ahmed ${ }^{2}$, Syed Zain Azher ${ }^{2}$ \& Shaikh Muhammad Tahir ${ }^{2}$ \\ 1. Fatima Jinnah Dental College \\ 2. Advance Educational Institute \& Research Centre (AEIRC) \\ Corresponding Author Email: maria3188@gmail.com
}

\begin{abstract}
Despite great deal of popular research interest in existence and altered body responses of emotional stress there are still strong arguments regarding its positive and negative impact on psychophysiological health. Stress is a state of mental or emotional strain or suspense and also a number of normal reactions of the body (mental, emotional, and physiological) and designed for self-preservation. The potentially lethal consequences of emotional stress are deeply rooted in folk wisdom, as reflected by phrases such as scared to death and a broken heart. In the past decade, cardiac contractile abnormalities and heart failure have been reported after acute emotional stress. a cross sectional study, data was collected by means of structured questionnaire from 370 subjects (age ranges between 20-50 years). Stress was accessed by using Sadaf Stress Scale (SSS) which comprises of 114 items divided into seven subscales data was analyzed by using SPSS 20.0. The main findings of this study are that emotional stress has a direct relation with age. People ranging below 30 years showed emotional stress and women being remarkably more susceptible to it.
\end{abstract}

\section{KEYWORDS}

Emotional stress, Stress, Sadaf stress scale, Acute emotional stress, Population

\section{INTRODUCTION}

Pakistan present status is being relatively undependable (WHO, 2006) and is becoming feebler with every passing day as continuous existence of roller-coaster political history which has extended the frustrated state as expressed in Pakistan (Easterly, 2001).With consistent stress, abundant terrorist attacks, inexistence of social security and starvation, Pakistan is rapidly becoming a "psychological pressure cooker" (Jamali, 2000). There is contagious Post-Traumatic Stress Disorder (PTSD) in Pakistan (Hashmi, 2011) due to anxiety induced by scarce basic essentials, religious extremists, social catastrophe, diminished income, and illiteracy (Jamal, 2006).It is well recognized that when your physical well-being is not endorsed and you don't have enough to feed your children your mental health is not a preference but the pressure indirectly or directly affects most of the population psycho-physiologically either as chronic or acute stressors (Sonnentag, 2006). On the whole pattern of physiological, emotional, cognitive and behavioral response to a number of immense challenging facets can lead towards abnormal suppressed situations that can be termed as stress (Fonagy, 2001). The overall mechanisms is a whole set of events and biological remodeling which have the ability to acknowledge stressors (Anisman,1999).There are uncounted sources of stress known as stressors (Lazarus, 1986) from any disheartening or complicated event in life to manage threatening surplus pressures (Hoehn, 1997). It is important to bear in mind that stress is a self-absorbed, subjective involvement and therefore what one person finds stressful another may not (Wegner, 1987). The overall mechanisms is a whole set of events and biological changes with respect to have the ability to respond to stressors (Anisman, 1999). The past 2 decades have seen a dramatic increase in factors affecting physical and mental health consequences of traumas, negative events, and chronic strains. Psychosocial burden also account for stress with variability in terms of gender, race, ethnic, age, marital status, and socioeconomic status differences in physical and emotional wellbeing. Any sort of emotional interruption can be computed as emotional stress whether acute or chronic. It can lead to significant chronic health challenges because body cannot shield itself against the destruction that emotional stress quietly construct over time and experience with heavy physiological price for every feeling of anxiousness, tension, annoyance, irritation or even excitement at toxic level. These all emotions serve important purposes when they first arise. The danger is in experiencing these emotions on a chronic basis. Stress Hormones commonly known as Glucocorticoids \& catecholeaminess influencing a body to produce "fight or flight response", changes in heart rate and blood pressure mainly (Wegner, 1987).Emotional stress can be followed up by moods, irritability or short temper, agitation, inability to relax, feeling overwhelmed sense of loneliness and isolation, anxiety, bad temper, worrying, depression, sadness, feeling insecure, lack of focus, burnout, forgetfulness, crying spells, relationship conflicts and abnormal laughter.. It is widely recognized that sustained emotional distress in pregnant women may affect neuroendocrine development in the fetus and the formation of a secure attachment bond with the newborn and, consequently the socioeconomic level of child (Campbell, 1997; Jacobsen, 1999). Mumford in 1996 carried his study in rural areas of Pakistan. The outstanding finding of this study in Gujar Khan, as with the previous Chitral study saw a very high level of emotional distress and psychiatric despair among women. In discussing the Chitral results, it was suggested that while physical disease and poor diet might have played their part, the large difference in states of morbidity between men and women pointed to potent social aspects at work (Mumford, 1997).It has been exposed may times that emotional stress may be associated with countable changes in pulse rate, stroke volume, cardiac output, peripheral resistance, and arterial blood pressure and that anxiety may significantly increase the amount of work required of the heart. Such stress may be associated with physiologic transformations which decrease myocardial reserve through interference with the functional adequacy of the coronary circulation or through interference with the intrinsic cardiac mechanisms governing heart rate and impulse conduction (Duncan, 1950; Stevenson, 1949). A retrospective study of mentally defective children in Edinburgh confirms Stott's findings of a significantly higher incidence of severe emotional stress in the 
pregnancies of mothers giving birth to infants with Down's syndrome than in the mothers of non-mongoloid defectives (Drillien, 2008). It is suggested that endocrine disturbance resulting from emotional stress may be causatively associated with the chromosomal anomalies found in Down's syndrome. Emotional stress could be more frequently shown to precede coronary occlusion in younger than in older people (Fritz, 2004). It has been shown further (Wendkos, 1994; Stevenson, 1994 \& White, 1995) that the circulation in individuals with both normal and diseased hearts recovers from exercise inefficiently (thus prolonging the period of increased work) during states of emotional tension. These emotional disturbances caused continuous but modest increases in the 17-hydroxycorticosteroids in the blood and urine. Plasma steroid values remained within the normal physiological range under the influence of emotional upset. These changes were less than those observed following the intravenous administration of $\mathrm{ACTH}$, Piromen, insulin, or electroshock treatment and moderate exercise. Emotional stress can be divided into negative and positive aspects, negatively, Emotional stress, being such an event, might well be expected to participate in the precipitation of congestive failure in individuals with diminished cardiac reserve. (Wolf, 1964)

\section{METHODOLGY}

It was a cross sectional study conducted on general population of Karachi belonging to different casts and family background to get a snapshot view of the prevalence of stress, and to assess the different perceptions and reasons behind that type of stress. Data were collected randomly by means of structured questionnaire from 370 subjects of different organizations, age ranges between 20-50 years. Stress was accessed by using Sadaf Stress Scale (SSS) evaluation of stress by observing major signs \& symptoms, and classification of these symptoms in seven different classes of stress (Physical stress, Traumatic stress, Nutritional stress, Emotional stress, Mental Stress, Psychosocial stress \& Chemical stress) \& comprises of 114 items. This study was designed only to evaluate the rate of emotional stress with respect to age and gender however data was analyzed by using SPSS 20.0 version.

\section{RESULT}

This study shows that there is a significant correlation of emotional stress with gender; females were more emotionally stressed as compared to males, $9.8 \%$ females were severely stressed up on the other hand males were $7.0 \%$ (as shown in Table no. 1). Chi square test shows that significance value is 0.001 . Age was another factor which was positively correlated with emotional stress, out of 370 participants age ranges between 30 years and less showed severely emotional stressed up (as shown in table no. 2). However result also shows that individuals with increasing age emotional stress reduces.

\begin{tabular}{|cc|c|c|c|c|c|}
\hline \multirow{2}{*}{} & \multicolumn{6}{|c|}{ Emotional Stress } \\
\cline { 2 - 7 } & Male & Normal & Mild & Moderate & Severe & \\
\hline \multirow{2}{*}{ Gender } & $73.0 \%$ & $11.3 \%$ & $8.7 \%$ & $7.0 \%$ & $100.0 \%$ \\
& Female & $74.1 \%$ & $10.2 \%$ & $5.9 \%$ & $9.8 \%$ & $100.0 \%$ \\
\multicolumn{2}{|c|}{ Total } & $73.8 \%$ & $10.5 \%$ & $6.8 \%$ & $8.9 \%$ & $100.0 \%$ \\
\hline
\end{tabular}

Table 1: Shows emotional stress level with respect to Age

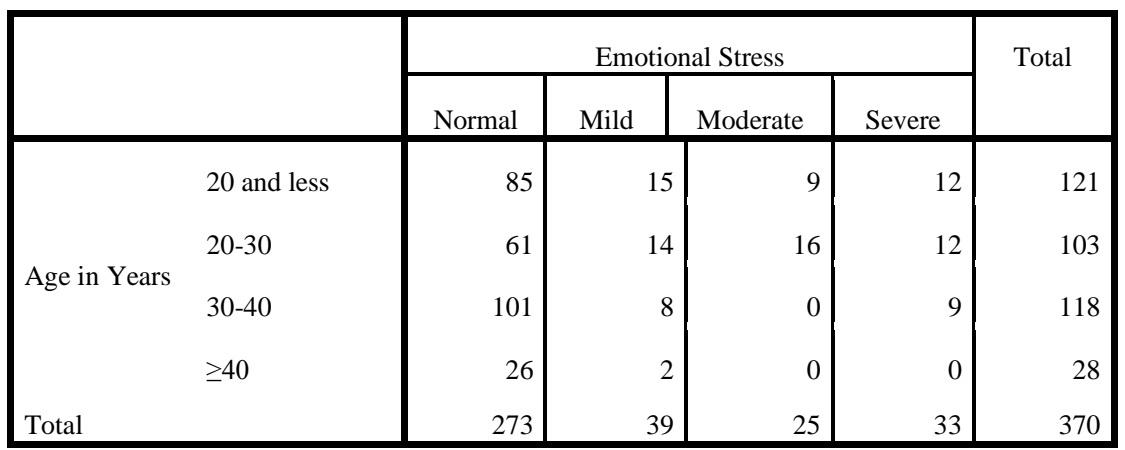

Table 2: Shows emotional stress level with respect to Gender 


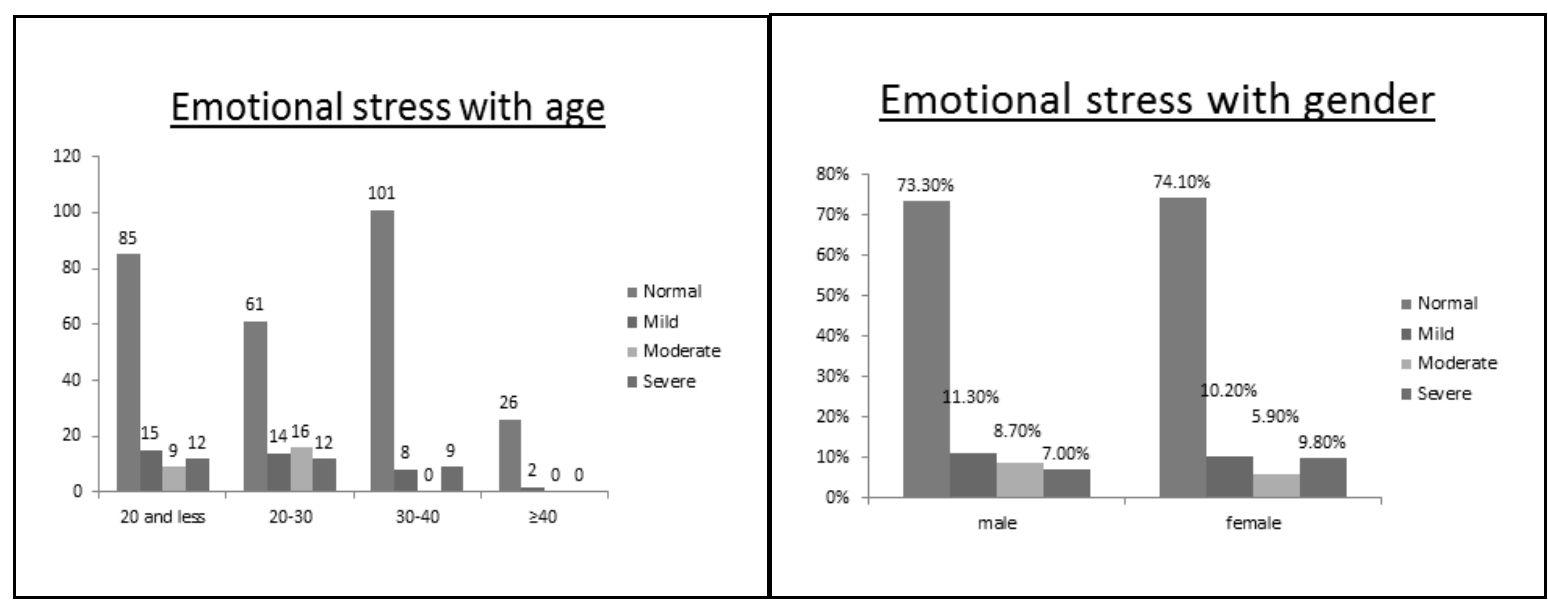

Graphical representation of emotional stress with age

Graphical representation of emotional stress with gender

\section{DISCUSSION}

Stress can be defined in several ways and it is important to use an approach that covers the different aspects of the concept. This study was performed to evaluate the level of emotional stress in Karachi. The result of this study shows that the subjects belonging to age group 20-30 years or less were more towards emotional stress as compared to other age groups. The present results indicated that women had a higher score in all stress components as compared to men. Women are socialized to be the caretakers of others. More women than men have both a career outside the home and continue to try to juggle traditional responsibilities after hours. Sociologists describe women as struggling to achieve the "male standard" at work, while trying to maintain the perfect wife and mother standards at home. Moreover previous studies report that there is a difference between the two sexes regarding empathy and self-control. The women are more stressful than men because they are more influenced by self the ideal women have skills in understanding and revealing their feelings, but men have more ability in controlling impulse and tolerating stress (Sanchez-Nunez, 2008) Besides The reason behind women being more physically stressed is: they are less likely to be in as powerful positions as men to change their environment. Women find it harder to say no to others requests and often feel guilty if they can't please everyone. They often spend less time nurturing their own emotional and physical needs, as that might be perceived as selfish. Emotional stress is a mostly occurred precipitating factor in the progression of congestive heart failure in the patient with limited cardiac reserve. It has long been accepted that disastrous or overwhelming emotional trauma (such as the death of a spouse or a narrow escape from accidental death) may be followed by an episode of failure in the cardiac patient. The fact that such major events occur relatively infrequently has led to, the tacit assumption that anxiety or emotional tension operate only infrequently as contributory or precipitating factors in most cases of I heart failure (Hickam, 1948), therefore stress management is needed. Clinical studies of yoga suggest that yoga breath interventions could target the symptoms of PTSD, depression and anxiety (Brown, 2005).Moreover, the voluntary use of deferent breath patterns can account for up to $40 \%$ of the variance in emotions, particularly anger, fear, joy and sadness (Philippot, 2002).
Emotional stress leads to severe menace in health issues depending upon its severity it has always been considered that emotional stress may be a precipitating factor in congestive heart failure, in this series it was found with greater frequency than had previously been anticipated. It was felt that emotional factors played a primary role in the precipitation of congestive failure in $19(76 \%)$ of the 25 consecutive cases studied. Each of them had, at the time of study, markedly limited cardiac reserve, and had been living under severe, chronic emotional strain. However, in each of these 19 patients the superimposition of an acute and overwhelming emotional experience was the factor immediately responsible for throwing him (or her) into cardiac decompensation. Although avoidance of life situations likely to produce emotional or mental stress may be desirable for many individuals, this is seldom feasible. Instead, to promote healthy living in general, patients who have experienced cardiovascular events during stressful experiences are advised to focus on strategies to reduce cardiovascular reactivity to acute (Campbell, 1997).

\section{CONCLUSION}

There is a need of such approaches like social support, relaxation therapy, yoga, meditation that not only manages emotional stress in affected populace but also merit additional investigation and debate on this important health issue.

\section{REFFERENCE}

- Anisman, H., \&Merali, Z. (1999). Understanding stress: characteristics and caveats. Alcohol Research and Health, 23(4), 241-249.

- Brown, R. P., \& Gerbarg, P. L. (2005). Sudarshankriya yogic breathing in the treatment of stress, anxiety, and depression: Part II-clinical applications and guidelines. Journal of Alternative \& Complementary Medicine, 11(4), 711-717.

- Drillien, C. M., \& Wilkinson, E. M. (2008). Emotional stress and mongoloid births. Developmental medicine and child neurology. 140-143.

- Easterly, W. (2001). The political economy of growth without development: A case study of Pakistan. Paper for the 
Analytical Narratives of Growth Project, Kennedy School of Government, Harvard University

- Fritz, D., (2004). Role of emotional stress preceding coronary occlusion. American journal of cardiology. 590-596.

- Hashmi, S., Petraro, P., Rizzo, T., Nawaz, H., Choudhary, R., Tessier-Sherman, B.,\& Nawaz, H. (2011). Symptoms of anxiety, depression, and posttraumatic stress among survivors of the 2005 Pakistani earthquake. Disaster medicine and public health preparedness, 5(4), 293.

- Hoehn, T., Braune, S., Scheibe, G., \& Albus, M. (1997). Physiological, biochemical and subjective parameters in anxiety patients with panic disorder during stress exposure as compared with healthy controls. European archives of psychiatry and clinical neuroscience, 247(5), 264-274

- Jacobsen, T. (1999). Effects of postpartum disorders on parenting and on offspring. Postpartum mood disorders, 119139.

- Jamal, A. (2006). Gender, Citizenship, and the Nation-State in Pakistan: Willful Daughters or Free Citizens? Signs, 31(2), 283-304.

- Jamali, A. R., Ghulamullah, S., Qureshi, I., \& Mehboob, G. (2000). Human cost of political violence. Journal Pakistan Medical Association, 50(1), 25-28.

- Lazarus, R. S., \& Folkman, S. (1986). Cognitive theories of stress and the issue of circularity. In Dynamics of stress (pp.63-80). Springer US

- Mumford, D. B., Irza, K. (1997). Socio-economic Scales for Pakistan. Pakistan journal of Clinical Psychiatry in press.
- Philippot, P., Chapelle, G., \&Blairy, S. (2002). Respiratory feedback in the generation of emotion. Cognition \& Emotion, 16(5), 605-627.

- Sanchez-Nunez, M., Fernandez-Berrocal, P., Montanes, J., \& Latorre, J. M. (2008). Does Emotional Intelligence Depend on Gender? The Socialization of Emotional Competencies in Men and Women and Its Implications. Electronic Journal of research in educational psychology, 6(2), 455-474.

- Sonnentag, S., \& Fritz, C. (2006). Endocrinological processes associated with job stress: Catecholamine and cortisol responses to acute and chronic stressors. Research in occupational stress and well-being, 5, 1-59.

- Stevenson, I. P., Duncan, C. H., \& Wolff, H. G. (1994). Circulatory dynamics before and after exercise in subjects with and without structural heart disease during anxiety and relaxation. Journal of Clinical Investigation, 28(6 Pt 2), 1534.

- Wegner, D. M., Schneider, D. J., Carter, S. R., \& White, T. L.(1987). Paradoxical effects of thought suppression. Journal of personality and social psychology,53(1), 5-13.

- Wendkos, M. H. (1944). The influence of autonomic imbalance on the human electrocardiogram: I. Unstable T waves in precordial leads from emotionally unstable persons without organic heart disease. American Heart Journal, 28(5), 549-567.

- White P. (1995). Heart disease (ed. 3). New York, Macmillan, p. 753. 